\title{
The System of Values of the Monotheistic Druze Managers from Israel Based on the Schwartz Theory of Human Basic Values
}

\author{
Radwan MANSOUR ${ }^{1}$ \\ Nicolae BIBU ${ }^{2}$
}

\begin{abstract}
This article is discussing the values that are specific to managers belonging to the Druze community from Israel. The Druze community is an ethnic community having some very unique characteristics, possessing an identity based on a mystic emotional connection which originates from heart and soul, a cross-border connection that brings together the ancient past, the present and the future without territorial identity. When the value system is understood and accepted by the organizational members and managers, they are committed to it and bear responsibility for their actions. Therefore, there is integration, dialogue, nourishment and balance between the particular desires for responsibility and the commitment to the organization.
\end{abstract}

Keywords: Druze community, human value, principals' values

JEL classification: I21

DOI: $10.24818 / \mathrm{RMCI} .2019 .4 .384$

\section{Introduction}

Our research is based on model of Prof. Shalom Schwartz (1992), using the PVQ 40 Value Scale. The results indicate that the values of conformity, tradition, universalism and security include preservative and survival elements that sustain the communal collective character. Also, the values of benevolence, achievement and self-direction are important to all managers in all age groups, in which benevolence values embody assistance to others, tolerance, integrity, loyalty and responsibility.

\section{The Monotheistic "Druze"}

The Monotheistic "Druze" community is a unique group of ethnic, religious, cultural and geographic aspects. It is an ethnic community having some very unique characteristics, possessing an identity based on a mystic emotional connection which originates from heart and soul, a cross-border connection that

${ }^{1}$ Radwan Mansour, West University of Timisoara

${ }^{2}$ Nicolae Bibu, West University of Timisoara 
brings together the ancient past, the present and the future without territorial identity. This community has an unique religious social infrastructure and its members live in a closed social circle without any option for outsiders to join it. Their lifestyle is usually characterized by a traditional lifestyle, distinctly primordial that strengthens social ties, mutual and social responsibility among its members while the religious infrastructure increases their hold on their culture and religion.

There is disagreement about the time and place of the formation of the community of the monotheistic "Druze", the "Druze", The Monotheists, "ALMohdoon A-Druz", the development of their religion and beliefs; although there are the results of different oppinion of researchers from various fields who attempted to study the historical, anthropological, social, hereditary, Faith and heritage, but there is a lot of hidden and contradictory between these various aspects.

The historical approach points to the formation of the religion of the monotheists"Druze" in the eleventh century CE in Egypt. The monotheistic "Druze" is a group that it is impossible to belong to it, a cohesive religious minority, which is characterized by mutual trust among its members, multiplies the sense of belonging and identity among them. This group, as we shall discuss below, has a unique social religious infrastructure that expresses the identity of a minority. The religious infrastructure of the unique the monotheistic "Druze" strengthens their hold on their culture and religion and the social infrastructure strengthens their harmony among themselves. The social cohesion and responsibility of anyone to other community member, it is therefore clear that these the monotheistic "Druze" are an entirely independent ethnic political group that lives in a tightly closed social circle (Al-Halabi, 2008).

The Principle of the Monotheistics' religion that monotheism is the faith and recognition of one and single God who is complete and pure, this is the first and the most important commandment in religion. There is a clear distinction between the essence of God and His descriptions and a complete separation between Him and His Creatures. There is no comparison between God and His Creatures, and no physical or human traits to be attributed to Him. (Al-Halabi, 2008).

The State of Israel did not make the monotheistic "Druze" equal to the Jewish residents in their rights even though they fulfill all their obligations because its being the state of the Jews. On the other hand, they do not see themselves as having an Arab identity, and the Arabs do not see them as part of the Arab nation in Israel (Halabi, 2008), so they did not belong to either of them. The consequence is that the identity of the monotheists "Druze" is not necessarily clear, it is an ambiguous and complex identity which has conceptual, psychological, and behavioral implications for the individual and the group (Lafromboise et al., 1993).

This community is currently in a transitional period, from a traditional society that, willingly or unwillingly, became a patriarchal society and is now transforming into a modern or semi-modern society. This transition involves significant changes, placing this community under complex challenges and tests. 
This transition is accompanied by crises and an increasing distance between on one hand, the community and its young members, who are the majority, and, on another hand, the religious, local and national leadership. The absence of a dialogue with the religious camp creates tension between the religious and the conceptual mind open to changes, to the environment and to modernity, which will all be examined in this article in relation to the current value system of Druze managers from Israel.

There is diverse and broad literature on the subject of values that include typologies that are found in research identified as having core values at different levels. Political core values such as equal opportunity, individuality, and free enterprise (Schwartz, Carpara \& Vecchione, 2010), personal values that affect daily behavior, social values and family values, traditionalism, equal opportunity, and moral tolerance (McCann, 1997, Goren, 2005).

Different researchers converged between political values and personal values. Thus, positive statistical correlations were found between people's trust in governmental institutions and conformity and traditional values. However, selfdirection as a value was found to be negatively correlated with trust in government institutions. Research showed that religious-oriented people consider supernatural leadership, divine power, God, while non-religious / secular people considered tangible and material things. Researchers found significant correlation between personal values: security, conformity and tradition, and family-related values: blind patriots, law and order, and militancy. On the other hand, there was clear negative correlation between personal values and political values of equality, civil rights, and acceptance of immigrants. It was also found that personal values of universalism, self-direction and benevolence had negative correlation to patriotism. Family traditional values, law and order, and militarism were found to have a clear positive correlation to political values such as equality, civil rights, and acceptance of immigrants (Schwartz,et al, 2001).

Management by values and value conduct is essential to keep a sustainable organization over time. When the value system is understood and accepted by the organizational members, they are committed to it and bear responsibility for their actions. (Dolan et al., 2007). Therefore, there is integration, dialogue, nourishment and balance between the particular desires for responsibility and the commitment to the organization. The values create an organizational identity and give the organization uniqueness and meaning, a relationship of mutual influence, and commitment based on common norms and values, on the organizational level and as an organizational theoretical model and not as a historical event (Dolan and Richley, 2006),

One of the major models in literature that developed the typology of personal values is the model of Schwartz (1992). Prof. Shalom Schwartz is one of the most prominent theorists in the research of values who developed a theory of values and a scale for its measurement. This theory consists of two aspects: a content aspect, which maps the content world of values in ten different motivational categories, and a structural aspect, which defines their 
interrelationships (Knafo and Schwartz, 2003). In the content aspect, Schwarz's theory of values defines values as desirable super-goals. This is differentiated in its importance, which people use as guiding principles in their lives, when the main factor that distinguishes between values is their motivational purpose. These goals are divided into ten types of values: power, achievement, hedonism, stimulation, self-direction, universalism, benevolence, tradition, conformity and security. These values represent different goals that's are summarized in three universal needs for human existence: needs of individual as a biological creature, need for social interaction and survival and welfare needs of the entire society.

The Power value is defined as: a search for status, prestige and control over people and resources. The Achievment value consists of achieving personal success by demonstrating abilities according to social expectations. The value Hedonism corresponds to a search for pleasure and personal delights. The value Stimulation is a search for thrills and challenges in life. The Self-direction value is defined by self-thought, autonomy, self-choice. The Universal value refers to understanding, acceptance, and tolerance for the well-being of others and of nature as a whole. The Benevolence value consists of the preservation and empowerment for the welfare of people with whom we have regular personal relationships. The value Tradition corresponds to respect, commitment, acceptance of leaders, ideas, traditional culture and religious determinations. The value Conformity refers to self-discipline, avoiding actions that may hurt others or violate accepted social expectations and norms. The Security value refers to personal and collective security, harmony, social and national stability, stability in relationships and emotional stability.

The realization of a certain value is an attempt to achieve a goal that underlies it. For example, realization of the value of Achievement expresses the goal of achieving social recognition. The goals differ in importance, correspond to different situations and serve as guiding principles in people's lives (Schwartz, 1992).

The values affect a person when they are relevant, important to oneself and less affective when are of lesser importance. The theory points dynamic connections between the types of values and creates a circular structure of similar values and opposing values. While the values that reflect opposing goals face each other and matching goals are adjacent to each other. For example, self-promotion stands opposite to promoting the other and the conservatism opposed to openness to change. Hedonism and stimulation are adjacent to each other and represent a pursuit of pleasant emotional arousal. In contrast, the types of opposing values that appear in opposite directions from the center of the circle represent conflicting motivations. For example, the value of achievement, which emphasizes striving for personal success, is likely to conflict with the kindness value, emphasizing activities for the welfare of others. (Schwartz, 1992).

Schwartz theory defines that each person has a hierarchy of more important and less important values. Therefore, human behavior will vary according to this hierarchy. However, all values can be cataloged and reduced to ten basic values. 
Despite the differences between cultures, there is a similarity in the hierarchy of values (Schwartz, 1992)

These ten values have also been identified in other studies about different cultures around the world and are therefore the basic values that build human characteristics. These values represent different goals that can be divided into three universal needs essential to human existence: the individual's needs as a biological creature, the individual's need for social interaction, and the society's survival and welfare needs as a whole (Schwartz et al., 2012).

The values are defined in the literature as criteria that guide people according appropriate behavior in different situations. Each person has a set of similar values, which differs in the level of importance of oneself. Due to the differences in the value scale, different people will act similarly to other people who act by the same values, and differently from people with other values.

Since people differ from each other by the importance, they attribute to different values according to the hierarchy of values of each individual. This hierarchy reflects the temperament and personality of the individual life experiences, culture, and guides one's perceptions, evaluations, and behavioral choices. In many cultures there is a consensus about the priorities of various values, despite the similarity on a group level, there are many inter-personal differences in one's priorities when choosing values (Schwartz, 2003: Schwartz and Bardi, 2001; Schwartz, 1992).

\section{Research methodology}

We have used a mixed research methodology, quantitative and qualitative. The quantitative part was based on a survey of the managers set of individual values. We have employed two questionnaires for the survey. The first questionnaire is the Portrait Values Questionnaire (PVQ), developpped by (Schwartz, 2003). The PVQ was designed to measure the same ten basic value orientations measured by the Schwartz Value Survey. It comprises 40 statements of person profiles, with 6 answers to each. See Table 1 for the the Scoring Key for PCQ 40 Value Scale. The second questionnaire is a socio- demographic questionnaire, including personal details such as age, gender, place of residence, education, lifestyle.

Table 1. The Scoring Key for PVQ 40 Value Scale

\begin{tabular}{|l|l|l|}
\hline No. & \multicolumn{1}{|c|}{ The value } & \multicolumn{1}{c|}{ The questions } \\
\hline 1 & Conformity & $36,28,16,7$ \\
\hline 2 & Tradition & $38,25,20,9$ \\
\hline 3 & Benevolence & $33,27,18,12$ \\
\hline 4 & Universalism & $40,29,23,19,8,3$ \\
\hline 5 & Self-direction & $34,22,11,1$ \\
\hline 6 & Stimulation & $30,15,6$ \\
\hline
\end{tabular}

$388 \quad$ Volume 20, Issue 4, October 2019 Review of International Comparative Management 


\begin{tabular}{|l|l|l|}
\hline No. & \multicolumn{1}{|c|}{ The value } & \multicolumn{1}{c|}{ The questions } \\
\hline 7 & Hedonism & $37,26,10$ \\
\hline 8 & Achievement & $32,24,13,4$ \\
\hline 9 & Power & $39,17,2$ \\
\hline 10 & Security & $35,31,21,14,5$ \\
\hline
\end{tabular}

The score given to each value is embedded in the weighted mean of all the questions relating to that value based on the distribution listed above in the scoring key. However, individuals and cultural groups are not uniform and differ even in reference to the response scale (Saris, 1988), so this variability can distort the findings and lead to incorrect conclusions (Schwartz, 1992).

The PVQ uses short descriptions of 40 different people, gender-matched with the respondent (Schwartz, 2005b; Schwartz, et al., 2001). Each description expresses either an individual's goals, personal aspirations, or wishes that relate implicitly to the importance of a value.

For each description the respondents answer to the questions: "How much like you is this person? Responses can be chosen from the following six: very much like me, like me, somewhat like me, a little like me, not like me, and not like me at all. We have inferred the respondents' own values from their self-evaluated similarity to the people in each description. The score for the importance of each value is the average rating given to these items, all of which were designated a priori as markers of a value (see Table 1).

To correct the scale and prevent discrepancies in the findings and results we did the following steps: we summed the values' scores and calculated the mean according to the index table above and examined the internal reliability of ten values. Second, we calculated the means of all 40 questions and prepared a MART for each item (Schwartz, 1996) and thirdly, we centralized the ten value scores as they appeared in the first step due to the individual means of MART (i.e., we subtract MART from each of the 10 value scores). Next, we have analyzed the correlation, we used the centered value score as appears in step three above. In order to compare group means, variance analysis or correlations we used t-test and ANOVA. We calculated the centered value scores as a dependent variable.

We used the scores of the answers of the questionnaire's items or in ten values means for doing multidimensional analysis, canonical analysis, isolated analysis, factor analysis (Schwartz, et al: 1997).

The sample population of the study is represented by 233 Druze managers $b$ elonging to the monotheistic "Druze" community in Israel. The participants in the research are from 19 villages with Druze population, belonging to 2 administrative districts and 5 different regions of Israel. The participating managers had diverse occupation areas and were a representative sample of the community's internal structure and its unique characteristics in Israel.

A great majority (99\%) of the participants were born in Israel; this situation is explained by the fact that the Golan Heights were part of Syria until 1967 and 
were occupied by the Israel defense forces in the "Six days war" that same year. The monotheistic Druze population, who lived in the Golan Heights villages during the war, stayed at home and did not abandon their villages, that leads us to the conclusion that some of the responding managers were originally born in Syria and today live in Israeli territory. According to participating managers' age the results show that $60 \%$ of them are under the age of 50 . This sample is consistent with the actual population structure, i.e., the young population is the largest mass, while the elder population is reducing over time.

Table 2. Statistics of the main research variables for all the Monotheistic "Druze" respondents

\begin{tabular}{|c|c|c|c|c|c|c|c|}
\hline Variable & Mean & $\begin{array}{l}\text { Standard } \\
\text { deviation }\end{array}$ & $\begin{array}{l}\text { Valid N } \\
\text { sample }\end{array}$ & $\begin{array}{c}\text { Range } \\
\mathbf{R}\end{array}$ & $\begin{array}{c}\text { Cronbach } \\
\text { ó } \\
\text { reliability }\end{array}$ & $\begin{array}{c}\text { Total } \\
\text { items } \\
\text { (questions) }\end{array}$ & Scale \\
\hline $\begin{array}{l}\text { Self } \\
\text { enhancement/ } \\
\text { Glorification }\end{array}$ & & & 233 & & -0.203 & 10 & $1-6$ \\
\hline Power & .84 & -.89 & 233 & 4.90 & & 3 & $1-6$ \\
\hline Achievement & 64 & .13 & 233 & 5.00 & & 4 & $1-6$ \\
\hline Hedonism & 95 & -.29 & 233 & 4.88 & & 3 & $1-6$ \\
\hline $\begin{array}{l}\text { Self- } \\
\text { transcendence/ } \\
\text { Promoting the } \\
\text { other }\end{array}$ & & & 233 & & 0.422 & 10 & $1-6$ \\
\hline Universalism & .43 & .41 & 233 & 3.08 & & 6 & $1-6$ \\
\hline Benevolence & .46 & .4 & 233 & 2.85 & & 4 & $1-6$ \\
\hline $\begin{array}{l}\text { Openness to } \\
\text { change }\end{array}$ & & & 233 & & 0.231 & 7 & $1-6$ \\
\hline Stimulation & .86 & -.46 & 233 & 4.99 & & 3 & $1-6$ \\
\hline Self-Direction & .51 & .41 & 233 & 3.18 & & 4 & $1-6$ \\
\hline Conservatism & & & 233 & & 0.441 & 13 & $1-6$ \\
\hline Tradition & .82 & -.76 & 233 & 4.60 & & 4 & $1-6$ \\
\hline Conformity & .59 & -.02 & 233 & 3.60 & & 4 & $1-6$ \\
\hline Security & .48 & .37 & 233 & 2.88 & & 5 & $1-6$ \\
\hline
\end{tabular}

\section{Discussion of Results}

Examining the results (see Table 2) for the ten leading values among the monotheistic Druze participating managers indicated that these values can be divided into five groups of supposedly new factors or variables, specific to Druze culture. In our opinion, there are a conservative factor that includes conformity and tradition values, a survival factor that includes achievement and security values, an individualistic business factor that includes self-direction and hedonism values, a 
collectivistic spiritual factor that includes universalism and benevolence values, and an opinionative daring factor that includes stimulation and power values. See Figure 1, below, for all participants.

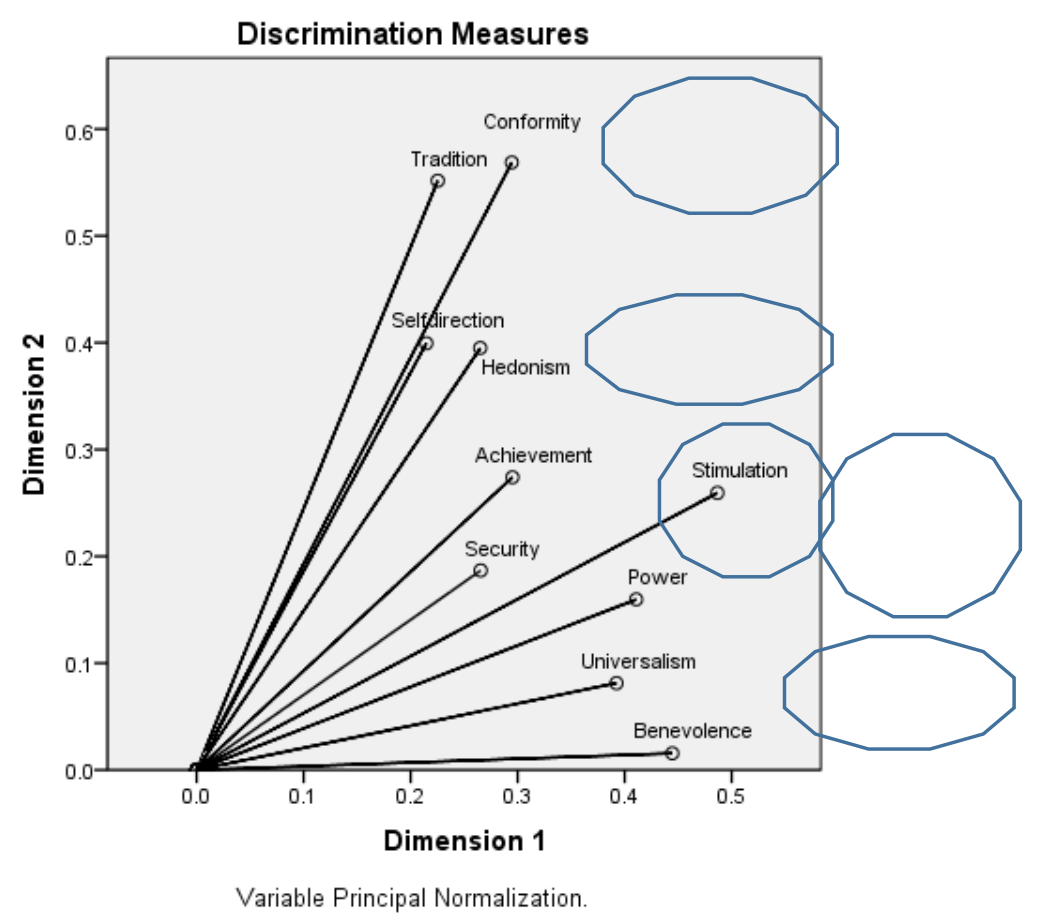

Figure 1. Reduction Scale/ Multiple Correspondence for All Participants

Our research shows that the values of conformity, tradition, universalism and security are especially important to managers of all age groups in the monotheistic Druze community. The values of conformity, tradition, universalism, and security which characterize the monotheistic Druze managers, as demonstrated in this research, include preservative and survival elements that sustain the communal collective character. They integrate with the religious principles of mutual responsibility and social solidarity characterizing the monotheistic "Druze". These social values are faithful to the monotheistic Druze collective that are strictly kept. These values are consistent with the social and religious values of the monotheistic Druze community, as social solidarity is accepted in this community, a high level of family, and communal and religious solidarity. This community is known for its ability to unite in times of trouble and protect the collective and the individual who need help and support. Despite the fact that sometimes the community members are separated by political borders defined by rival political entities, they continue to display responsibility and mutual social guarantee, social solidarity in times of crisis and individualism in tranquil and routine times. The conformity and tradition values also connect to an additional element: acceptance that the monotheistic 
Druze define as a divine decree. The principle of "A-Reda and A- Taslim" is accepted, whatever may be, with complete willingness and compliance and without any objection.

As mentioned above, the universalism and security values are especially important to all managers participating in this research. These values are well connected with main social principals and elements prevalent among the monotheistic Druze. Universal value symbolizes the belief that the law's equality applies to all people, the level of understanding, appreciation, patience and protection of the other's welfare and of nature and preservation of a harmonious life, are developed among them. This value embodies social justice and equality. Similarly, the belief in reincarnation which is deeply embedded among monotheistic Druze, is considered as a divine justice mechanism, divine wisdom, and part of God's mercy toward creatures, in which man was given a repetitive opportunity to be born as a human being and live in different times and conditions from the creation of the world until the divine doomsday. This reincarnation transfers the compassion from one person to another since they do not know where they will be born and with whom. The monotheistic Druze religion strictly forbids and even punishes any of its members who take lives of others and those who violate social norms that preserve the collective. This belief instills compassion and which is passed down through reincarnations of the souls of the managers and other community members.

This research shows that security value is significant, oriented towards community, family and social responsibility/community solidarity, fundamental components and elements that are inherent in the monotheistic Druze belief and values. The value of security is probably based on religion and faith, on one hand, and on historical memory and religious principle of suffering and pogroms called "Mehan" that the monotheistic Druze experienced and believe will repeat in various forms. They believe the suffering, persecution, and harassment was and will ever be. Therefore, the security value is doubly significant, sufficiently rooted, and clearly expressed in a developed sense, in their daily conduct.

Analyzing these research results shows that the values of benevolence, achievement and self-direction are important to all managers in all age groups, in which benevolence value embodies assistance to others, tolerance, integrity, loyalty and responsibility. The values that express the religious foundations of mutual responsibility, solidarity in its broadest sense, and equality are based on the reincarnation principle.

The value of achievement creates enthusiasm and energies that nourish growth and help managers maintain a high level of performance over time in their organization. However, uncompromising achievement over time will damage the subordinates' morale and their achievements. There is no doubt that the drive to achieve is increasing lately. "The drive for achievement is on rise for the last 35 years as we evaluate managers' motivations, and over the last decade we have seen a consistent rise in the number of managers who see success as their main motive. The businesses gained of this trend: the labor productivity rose, the innovation that 
reflects in the number of patents published every year are skyrocketing" (Spreier et al., 2006).

The results show that monotheistic Druze managers are preferring a culture based on the cooperation and leadership when working in a group, a culture that balances between influence and assisting others and the drive for achievement. This culture contains the belief in the survival principles required due to the dangers kept in the collective memory that have pass from generation to generation and from reincarnation to reincarnation, knowing that the dangers/the pogroms, "Al Mehan", may repeat within the monotheistic Druze community at any place or time, without early notice or warning. Hence, it is important for Druze managers to adhere to the individual achievement as an individual and also to be a part of a collective that can help the people who believe in mutual responsibility and social solidarity.

According to this research, the self-direction value is based on the desire for independence in thinking and in daily activity, in openness to change, innovation, curiosity and creativity. The self-direction value seems to correspond to the element and value of assertiveness characterizing the monotheistic Druze. These values correspond with the monotheistic Druze's values and foundations of social solidarity that is understood in this community.

The power value data among religious managers of the monotheistic Druze community were found to be highly concentrated with a low variance level and low deviations. This is probably an expression of the conservatism characterizing this community. Conservatism that requires a traditional society that preserves classes, norms and customs, and respects the religious leadership rooted in the religious structure.

However, we must not forget that the power value and managers' motives can be expressed in two forms. The first is personal in which a manager gets their strength from the fact that they control subordinates, control resources and attract reverence and respect. The second form, is the social power value in which the power of the managers stems from the fact that they grant power and authority to others.

The research shows that the values of conformity, tradition, universalism and security have especially important to all respondent's managers in the monotheistic "Druze" community. This special importance is strongly connected to the transformational leadership. Values of Benevolence, Achievement, and Selfdirection are important for all age groups. The importance of Universalism, Security and Power values are directly correlated to respondents' age, while the values of Stimulation and Hedonism are indirectly correlated to the respondents' age.

Research results show that the values of Benevolence, Achievement and Self-direction are important to all managers in all age groups, indicating that they embody assistance to others, tolerance, integrity, loyalty and responsibility. Values that express the religious foundations of mutual responsibility, solidarity in its broadest sense, and equality are based on the reincarnation principle. This

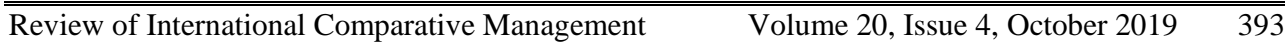


integrates with the religious principles of mutual responsibility and social solidarity which characterizes the monotheistic

"Druze" managers belonging to the religious group are more conformist, more traditional, more achievement, with more security values with low dispersion level and the median was higher than secular/non-religious managers. The Conformity and Tradition values have significant differences ( $p_{-}$value $\left.<0.05\right)$. The Self-direction value seem to correspond to the element and value of assertiveness characterizing the monotheistic "Druze" managers and appear to be social values that are loyal to the collective.

Female managers appear to be less traditional and conformist and more containing self-direction, hedonism, achievement and stimulation values, which are necessary for transformational leadership and transactional leadership. The managers of the monotheistic "Druze" community maintain the values they were raised and educated by, even when they are in a managerial status; a result that is in accordance with the research hypothesis, including values that preserve the unique character of the community and the values that characterize the survival elements.

\section{Conclusions}

The Druze system of values reflects the changes that are taking place The Box Plot diagram cut results as presented in this research showed that the leading values among the monotheistic Druze managers may be sorted by level of importance into three value types.

The first is the survival values that are expressed in two ways: the first, belonging to a broad and even universal collective and having benevolence and universalism values.

The second is personal empowerment through knowledge and status acquisition, including through values of achievement, self-direction and security. The second type of values is conservative values expressed in preserving collective uniqueness, solidarity, and social responsibility. These values are expressed in high level of conformity and tradition values.

The third type is personal and group satisfaction values along with stimulation and power values. It also appears that among women there is great importance to hedonism values, whereas the values of conformity and tradition are ranked on a relatively low importance scale. The hedonism values are on a high level on the importance scale among young managers aged 20-35. The conformity and tradition values, among monotheistic Druze managers, are on a high level on the importance scale, especially as managers grow older.

Overall, we conclude that the managers of the monotheistic Druze community maintain the values they were raised and educated by even when they are in a managerial status. These results indicate that the Druze managers are still holding the values that preserve the unique character of the community and the values that characterize the survival elements. 


\section{References}

1. Al-Halabi, A'bbas. (2008), Almowahdoon A-Druze: T'akafa, Tarikh w Resalh. (Themonotheists "Druze": Culture, History \& Message) Dar Anhar Press, Beirut, Lebanon.(Arabic).

2. Dolan, S. Gracia, S. Richley, B. (2007). Managing by Values, Palgrave Macmillan, UK.

3. Dolan, S. and Richley, B. (2006), "Management by values (MBV): a new philosophy for a new economic order", Handbook of Business Strategy, Vol. 7 No. 1, pp. 235-238.

4. Goren, Paul. (2005). "Party Identification and Core Political Values" American Journal of Political Sciences. Volume 49, Issue 4.Pages 881-896

5. Knafo, A., \& Schwartz, S. H. (2003). Parenting and adolescents' accuracy in perceiving parental values. Child Development, 73, 595-611.

6. Lafromboise, T. Hardin, 1. Coleman, K.\&Gerton, J. (1993). Psychological impact ofLandau, M. Jacob. The Arab Minority in Israel 1967-1991 Political Aspects, Hebrew University Press, 1993. (Hebrew)

7. McCcann, Graham (1977), Cary Grant: A Class Apart. London: Fourth Estate. ISBN 978-1- 85702- 574-3.

8. Schwartz, S. H. (1992). Universals in the content and structure of values: Theory and empirical tests in 20 countries. In M. Zanna (Ed.), Advances in experimental social psychology (Vol. 25, pp. 1-65). New York: Academic Press.

9. Schwartz S. H. (1996). Value priorities and behavior: Applying a theory of integrated value systems. In C. Seligman, J. M. Olson, \& M. P. Zanna (Eds), The Psychology Values: The Ontario Symposium, Vol 8 (pp. 1-24). Hillsdale, NJ: Erlbaum.

10. Schwartz S. H. and Bardi A. (2001), Value Hierarchies Across Cultures in Journal of Cross-Cultural Psychology. 32(3): 268-290 May 2001.

11. Schwartz, S. H., Melech, G., Lehmann, A., Burgess, S., Harris, M., \& Owens, V. (2001). Extending the cross-cultural validity of the theory of basic human values with a different method of measurement. Journal of Cross-Cultural Psychology, 32, 519-542.

12. Schwartz S. H. (2003). AA Proposal for Measuring Value Orientations across Nation. Chapter 7 in the Questionnaire Development Package of the European Social Survey. 